Anales de Literatura Hispanoamericana

ISSN: 0210-4547

http://dx.doi.org/10.5209/ALHI.58262

\title{
En el centenario de Rubén Darío (1916-2016)
}

Darío Villanueva ${ }^{1}$

Resumen. En el centenario de la muerte de Rubén Darío, su figura se une a la de otros grandes escritores que también han celebrado también los centenarios de sus muertes: Miguel de Cervantes y el Inca Garcilaso de la Vega. Todos ellos vienen a conformar la República universal de las Letras, junto al otro homenajeado en el año 2016, William Shakespeare. Más es hoy la figura de Darío de la que se parte y a la que se llega para reflexionar en torno a las literaturas en lengua española.

Palabras clave: Rubén Darío; centenario; viajeros; Cervantes; Machado.

[en] On the centenary of Rubén Darío (1916-2016)

Abstract. On the centenary of the death of Rubén Darío, his figure joins that of other great writers who have also celebrated the centenary of his death: Miguel de Cervantes and the Inca Garcilaso de la Vega. All of them come to conform the Universal Republic of Letters, together with William Shakespeare, the other one honored in 2016. More is today the figure of Dario from which we start and which is reached to reflect on the literature in Spanish language.

Keywords: Rubén Darío; centenary; travellers; Cervantes; Machado.

Como citar: Villanueva, D. (2017) En el centenario de Rubén Darío (1916-2016), en Anales de Literatura Hispanoamericana 46, 13-16.

Uno de los poetas españoles a cuyo descubrimiento y temprana fama más contribuyó el nicaragüense Rubén Darío con su indiscutible autoridad de precoz príncipe de las letras hispanas fue Antonio Machado, a quien se debe una de las definiciones de poesía que prefiero: palabra esencial en el tiempo. Efectivamente, los grandes poetas que en el mundo han sido perviven en nuestra memoria gracias a sus escritos y a la imprenta, "de injurias de los años vengadora" en expresión de otro escritor admirado por Darío en aquellos versos juveniles que rezan:

De Quevedo imitar quiero la sabia

Frase de fuego de sagrado encono, Y castigar a aquel que nos agravia.

Los clásicos perduran porque nos imitan, porque siguen diciendo con las palabras mejores en el orden mejor aquello que el resto de los mortales

1 Director de la Real Academia Española y Presidente de la Asociación de Academias de la Lengua Española. 
experimentamos con nuestros sentidos y albergamos en nuestra más profunda intimidad sin que seamos capaces, como ellos, los poetas, de expresarlo cabalmente. De ahí lo justo de conmemorar sus efemérides, tanto las de su nacimiento, las de la publicación de sus obras más destacadas o de sus centenarios luctuosos.

Eso es lo que este año de gracia de 2016 todos los hispanohablantes y los ciudadanos de la República universal de las Letras vamos a hacer con Miguel de Cervantes, que falleció en 1616, unos pocos días antes que William Shakespeare. 1616 fue asimismo la data de la muerte de uno de los primeros grandes escritores nacidos del maridaje hispanoamericano, el Inca Garcilaso de la Vega, inmortal autor de los Comentarios Reales.

Pero estamos también conmemorando con la máxima dignidad y respeto otro centenario no menos trascendente que el de Cervantes, o los ya mencionados. El 6 de febrero de 1916 fallecía en la ciudad de León de Nicaragua Félix Rubén García Sarmiento, Rubén Darío, cuyos versos perviven por ser realmente palabras esenciales en el tiempo, y cuya importancia para el desarrollo creativo de la lengua española y de la poesía en ella escrita no fue menor, trescientos años más tarde, que la del manco de Lepanto para la prosa y la narrativa.

No creo equivocarme si afirmo que ambos, Cervantes y Rubén, Darío y don Miguel, constituyen las dos referencias indubitables para todos los que hablamos nuestra lengua común y amamos su literatura escrita en las dos riberas de la mar océana. De Cervantes se conserva una carta dirigida por el entonces escritor novel a don Antonio de Eraso, secretario del Consejo de Indias de Lisboa, a quien le confiesa la decepción que le había supuesto no ver atendida su solicitud de un puesto administrativo en América. Mantiene la esperanza, sin embargo, y lo cito textualmente, de que por una próxima "carabela de aviso" llegue noticia de una vacante, y entretanto se ocupará en escribir su novela pastoril La Galatea.

Don Miguel quiso, pues, renacerse como americano sin conseguirlo. Otra más de las decepciones y de los fracasos que jalonaron la vida de quien, sin embargo, en sus últimos años, escribió las dos partes del Ingenioso hidalgo y caballero don Quijote de la Mancha, obra genial que alumbró el nacimiento de la novela moderna y alcanzó en América un éxito temprano y sin precedentes. Rubén Darío tuvo más suerte: quiso hacerse ciudadano de todas las Américas: "Yo pan-americanicé", enuncia, con cierta jactancia, en la "Epístola a la señora de Leopoldo Lugones" incluida en El canto errante. Pero también pretendió hacerse español de España, y en ambos casos alcanzó su objetivo. A él pueden atribuírsele sus propios versos dedicados al peruano José Santos Chocano:

Va como Don Quijote en ideal campaña,

Vive de amor de América y de pasión de España.

Vetado su viaje americano, Cervantes fue solo viajero por España, por Portugal, por Italia y por el Mediterráneo en donde combatió "en la más alta ocasión que vieron los siglos" - para él, la batalla de Lepanto contra los turcos- y en Argel sufrió cautiverio. Rubén, por su parte, fue un viajero impenitente. Asombra como a lo largo de una existencia truncada a los cuarenta y nueve años de su edad, el poeta pudo vivir, escribir y, a la vez, viajar tanto. Y ello redundó en que se convirtiera 
para nosotros no solo el príncipe de nuestra poesía sino también en un oráculo de nuestra identidad hispánica.

Los acontecimientos históricos que a lo largo del siglo XIX jalonaron las independencias de las repúblicas americanas, concluidos en 1898, año en que Rubén Darío se desplazó por segunda vez a España, hicieron concebir al nicaragüense, en palabras del poeta mexicano José Emilio Pacheco, "la necesidad de un panhispanismo en ambos continentes". Esto es, la imprescindibilidad de ese impulso de solidaridad y cooperación idiomática entre los pueblos hispanohablantes que marca a lo largo de los últimos decenios la política lingüística panhispánica desarrollada por la Asociación de Academias de la Lengua Española (ASALE) que me honro en presidir.

Rubén fue un auténtico escritor cosmopolita, pero a la vez su biografía acredita un panhispanismo vital que aureola con una indiscutible impronta novelesca su vida, "escrita por él mismo" en 1912. Amén de su constante periplo por Honduras, El Salvador, Chile, Buenos Aires, Perú, Guatemala, Costa Rica, Cuba, Panamá y España, su posterior residencia en París como cónsul de su país facilitó sus viajes por la Europa continental, que en 1906 se interrumpieron por mor de su participación por parte de Nicaragua en la Tercera conferencia panamericana en Rio de Janeiro. Vienen luego México, Uruguay y Nueva York, hasta su fallecimiento en la ciudad de su infancia.. Nada más cierto que esta apreciación de Pedro Salinas: "Su vida era, por decirlo así, trasatlántica, y desde el continente donde residía seguía sintiéndose, en rara ubicuidad, en aquel otro que le faltaba".

Precisamente la generación española del 27, a la que pertenecía el poeta recién citado por mí junto al premio Nobel Vicente Aleixandre, Federico García Lorca, Jorge Guillén, Rafael Alberti o Luis Cernuda, no hubiese existido sin el ejemplo de Rubén Darío. Como tampoco el también ya citado Manuel Machado sería el mismo, ni otros tres premios Nobel como Juan Ramón Jiménez, Pablo Neruda o Gabriela Mistral. Lo mismo cabe decir de César Vallejo, de Vicente Huidobro, del propio Jorge Luis Borges, por citar tan solo a escritores no vivos. Y no lo digo solo yo. Con mayor autoridad, la de un gran poeta, el mexicano José Emilio Pacheco lo proclama así: "Era la lengua española toda la que resucitaba con Darío. Cuanto se escribió en el siglo XX hubiese sido inconcebible sin él (...) Del conflicto y el diálogo entre Europa y América, entre lo antiguo y lo moderno, extrajo un instrumento verbal que absorbió y transformó todo y abrió el camino a lo que sucedió después en la poesía y en la literatura de España y América”.

Bien es cierto que hubo quien quiso ridiculizar su Modernismo identificándolo con "cisnes, princesas, jardines versallescos, arte por el arte, evasión de la realidad, versos sonoros para ser declamados" (J. E. Pacheco). El propio Rubén ironiza sobre ello en su extraordinario poema autobiográfico "Versos de año nuevo", que era 1910, al que pertenecen estas palabras:

¡Yo soy el introductor

De esa literatura aftosa!

Mi verso exige un disector,

$\mathrm{Y}$ un desinfectante mi prosa. 
Pero la otra dimensión rubeniana, de extraordinaria densidad metafísica, de inmersión profunda en las miserias de la realidad e, incluso, de crítica social, está presente en su trayectoria desde sus comienzos. A los 18 años escribe ya, proféticamente,

Yo tengo tonos diversos

En las cuerdas de mi lira;

Hay en mis canciones ira

Y son mis frases puñales

Para ruines y desleales,

Para el dolo y la mentira.

Mas también tengo un laúd

De suave y tierna dulzura

Para cantar la hermosura.

La nobleza y la virtud;

Me da alas mi juventud,

Tengo fe en el porvenir.

Sin ella, sin esta fe, no podría haber escrito veinte años más tarde Cantos de vida y esperanza, y, en este poemario inolvidable, su "Salutación del optimista", uno de los himnos más vibrantes y conmovedores de toda la Hispanidad. Pero la obra termina con un poema sobrecogedor, una de las joyas de la poesía de todos los tiempos, titulado "Lo fatal". Dos años más tarde publicará El canto errante, dedicado "a los nuevos poetas de las Españas", en cuyo prólogo afirma algo que viene a completar el sentido de la definición de la poesía machadiana que hemos citado ya: "La poesía existirá mientras exista el problema de la vida y de la muerte. El don de arte es un don superior que permite entrar en lo desconocido de antes y en lo ignorado de después, en el ambiente del ensueño o de la meditación”. 